\title{
Comportamento de micro-organismos patogênicos durante processo de compostagem
}

\section{de carcaças de suínos}

\author{
Behavior of microbial pathogens during composting process of swine carcasses \\ Comportamiento de microorganismos patogénicos durante el proceso de compostaje en carcasas
}

porcinas

Recebido: 15/12/2021 | Revisado: 22/12/2021 | Aceito: 24/12/2021 | Publicado: 04/01/2022

Aline Viancelli
ORCID: https://orcid.org/0000-0003-1654-6510
Universidade do Contestado, Brasil
E-mail: alineviancelli @unc.br
Valdir Silveira de Avila
ORCID: https://orcid.org/0000-0002-5380-4251
Empresa Brasileira de Pesquisa Agropecuária, Brasil
E-mail: valdir.avila@embrapa.br
Sabrina Castilho Duarte
ORCID: https://orcid.org/0000-0002-3368-0351
Empresa Brasileira de Pesquisa Agropecuária, Brasil
E-mail: sabrina.duarte@embrapa.br
Everton L. Krabbe
ORCIDhttps://orcid.org/0000-0002-7520-058X
Empresa Brasileira de Pesquisa Agropecuária, Brasil
E-mail: everton.krabbe@embrapa.br
Suzana Satomi Kuchiishi
ORCID: https://orcid.org/0000-0002-8834-8129
Laboratório CEDISA, Brasil
E-mail: susana@cedisa.org.br
William Michelon
ORCID: https://orcid.org/0000-0003-0713-0150
Universidade do Contestado, Brasil
E-mail: william@unc.br

\section{Resumo}

O processo de compostagem é uma prática importante para aceleração da decomposição de carcaças e inativação de patógenos potencialmente presentes no material a ser decomposto. No entanto, é necessário avaliar e promover o funcionamento adequado do processo. Diante disso, o presente estudo teve por objetivo avaliar a eliminação de microorganismos patogênicos em composteiras construídas em escala laboratorial para decomposição de carcaças de suíno trituradas e em escala piloto para decomposição de carcaças de suíno em pedaços (picadas). Para isso, foram construídas composteiras em escala laboratorial e piloto, onde foram compostadas carcaças de suínos intercaladas com camadas de maravalha, umedecidas com água. A essas composteiras foram adicionadas concentrações conhecidas de micro-organismos patogênicos modelo (Escherichia coli e Salmonella Senftenberg). A redução destes micro-organismos foi acompanhada até a não detecção dos mesmos viáveis. Os resultados indicaram que as composteiras em escala piloto, devido às suas dimensões, atingiram as condições ideais de processo e eliminaram de forma eficiente e mais rápida os patógenos (até 7 dias, quando a temperatura atingida foi acima de $60^{\circ} \mathrm{C}$ ). Desta forma, este processo é uma alternativa promissora para a destinação de carcaças de suínos se executado dentro de condições adequadas.

Palavras-chave: Salmonella; E coli; Decomposição; Animais mortos.

\begin{abstract}
The composting process is an important practice for carcasses decomposition acceleration and inactivation of potentially pathogenic microorganisms present in the material to be decomposed. However, it is necessary to evaluate proper parameters of the process. Therefore, the present study aimed to evaluate the inactivation of pathogenic microorganisms in composters built in laboratory and pilot scale for decomposition of swine carcasses. For this purpose, composters were built on laboratory and pilot scale and known concentrations of pathogenic microorganisms were added (Escherichia coli e Salmonella Senftenberg). The reduction of these microorganisms was measured until there was non-detection of viable micro-organisms. The results indicated that the pilot-scale composting, due to their dimensions, reached the ideal process conditions and eliminated the pathogens more efficiently and quickly (in 7
\end{abstract}


days, when temperature was above $60^{\circ} \mathrm{C}$ ). Thus, this process is a promising alternative for the disposal of swine carcasses.

Keywords: Salmonella; E coli; Decomposition; Dead animals.

\section{Resumen}

El proceso de compostaje es una práctica importante para acelerar la descomposición de la carcasas e inactivar los patógenos potencialmente presentes en el material a descomponer. Sin embargo, es necesario evaluar y promover el buen funcionamiento del proceso. Por tanto, este estudio tuvo como objetivo evaluar la eliminación de microorganismos patógenos en contenedores de compost construidos a escala de laboratorio para la descomposición de carcasas de porcino molidas y a escala piloto para la descomposición de porcino molidas en trozos (picados). Para ello, se construyeron compostadores a escala de laboratorio y piloto, donde se compostaban las carcasas de porcino intercaladas con capas de virutas de madera, humedecidas con agua. Estos compostadores se agregaron a concentraciones conocidas de microorganismos patógenos modelo (Escherichia coli e Salmonella Senftenberg). Se siguió la reducción de estos microorganismos hasta que no se detectaron viables. Los resultados indicaron que los compostadores a escala piloto, por sus dimensiones, alcanzaron las condiciones ideales de proceso y eliminaron eficiente y rápidamente los patógenos (hasta 7 días, cuando la temperatura alcanzada era superior a $60^{\circ} \mathrm{C}$ ). Por lo tanto, este proceso es una alternativa prometedora para la eliminación de carcasas de porcino si se realiza en condiciones adecuadas.

Palabras clave: Salmonella; E coli; Descomposición; Animales muertos.

\section{Introdução}

A compostagem de animais mortos é uma prática amplamente utilizada na produção animal, especialmente suínos e aves, que tem por objetivo a decomposição de carcaças e a geração de compostos orgânicos para posterior utilização como fertilizantes (Gwyther et al., 2011; Gamroth, 2012). O processo de decomposição ocorre pela interação de parâmetros como temperatura, aeração e umidade, sem a qual a compostagem pode perder sua eficiência (Partanen et al., 2010; Ajmal et al., 2020). Esses parâmetros criam condições ideais para a ação de bactérias, fungos e outros organismos decompositores, isso significa que se houver mudanças nas condições de temperatura, aeração e umidade haverá interferência no grupo de microorganismos que será favorecido, e consequentemente na eficiência do processo (Bhatia et al., 2013; Palaniveloo et al., 2020).

$\mathrm{O}$ processo de compostagem geralmente apresenta quatro etapas principais: fase inicial, fase termofílica, fase mesofílica e fase de maturação (Sundberg et al., 2004; Chang et al., 2021). Na fase inicial, ocorre a multiplicação de bactérias mesofílicas, as quais liberam calor e por isso, contribuem com o aumento da temperatura do material compostado. Nesta fase, a temperatura média supera $45^{\circ} \mathrm{C}$ e a duração desta etapa está diretamente relacionada ao substrato utilizado (Cooperband, 2002; Nakasaki et al., 2019). Na fase termofílica, crescem as bactérias termofílicas e a temperatura média é elevada para $70^{\circ} \mathrm{C}$, tendo como consequência a decomposição da matéria orgânica. Nesta fase do processo, a elevação da temperatura pode atuar na eliminação de micro-organismos patogênicos que por ventura estejam na carcaça do animal, como as bactérias Salmonella spp. e Escherichia coli (Biswas et al., 2019; Lepesteur, 2020). Essa prática é importante, especialmente em se tratando de resíduos de origem animal. Na fase mesofílica ocorre a diminuição da temperatura do composto (resfriamento) e aumento da umidade (Liang et al., 2003; Wang et al., 2021). Por conta disso, há diminuição na atividade das bactérias e aumento da atividade de fungos. Nesta etapa, eventualmente, poderá ser realizado o revolvimento do material, para aumento da aeração, iniciando-se novamente a fase termofílica (Schloss et al., 2000). A fase de maturação ocorrerá quando o composto apresentar temperatura equivalente à temperatura ambiente (Costa e Akdeniz et al., 2019; de Mendonça Costa et al., 2021). O processo completo de compostagem ocorre em um período médio de 120 dias, após o qual a matéria orgânica se transforma em composto estabilizado (Saviozzi et al., 2004; Masin et al., 2020).

Técnicas como a compostagem tem sua importância embasada no cenário brasileiro devido ao país ser o quarto maior produtor de suínos do mundo (ABPA, 2021). Desta forma, mesmo com baixas porcentagens de mortalidades observadas nas granjas, essas carcaças precisam ser destinas de forma adequada para evitar problemas ambientais e sanitários (Pepin et al., 2020). 
No entanto, é necessário verificar a relação entre a temperatura da pilha de compostagem e a eficiência na inativação de micro-organismos patogênicos. Diante disso, o presente estudo teve por objetivo avaliar e eliminação de micro-organismos patogênicos em composteiras construídas em escala laboratorial e piloto para decomposição de carcaças de suíno trituradas e em pedações, respectivamente.

\section{Metodologia}

\subsection{Preparação de inóculo bacteriano}

Para obtenção do inóculo bacteriano, cepas de campo de Escherichia coli e Salmonella enterica sorovar Senftenberg (Bacterioteca 20404), foram cultivadas em ágar sangue a $37{ }^{\circ} \mathrm{C} / 18$ - 24h. O cultivo foi repicado em trypticase soy agar (TSA) e incubado a $37^{\circ} \mathrm{C} / 18$ - 24h. Após, o crescimento bacteriano foi utilizado para preparar suspensões (em solução salina 0,9\%) contendo concentração com equivalência ao tubo 3 da escala de McFarland, o qual foi diluído para que a concentração final no experimento contivesse $10^{6}$ Unidades Formadoras de Colônia (UFC mL ${ }^{-1}$ ). A preparação do inóculo bacteriano seguiu a metodologia descrita por Monteiro et al (2021).

\subsection{Compostagem em escala laboratorial}

Para essa etapa foram montadas composteiras experimentais $(1 \mathrm{~m} \times 1 \mathrm{~m}$, em triplicata) contendo 5 camadas, sendo a base formada por 4,5 kg de maravalha, seguida de $10 \mathrm{~kg}$ de carne suína triturada, e aspergida com $3 \mathrm{~L}$ de água livre de cloro, e novamente coberta por uma camada contendo $4,5 \mathrm{~kg}$ de maravalha. E assim seguindo até a quinta camada, finalizando com uma camada de 4,5kg de maravalha com fechamento final da célula. Juntamente com a água foram adicionados suspensões bacterianas contendo $10^{6}$ UFC de bactérias modelo ( $S$. Senftenberg) e $10^{6}$ UFC para E. coli. O experimento foi idealizado de acordo com estudos já publicados (Wilkinson, 2007).

\subsection{Compostagem em escala piloto}

Para a compostagem em escala piloto, foram utilizadas composteiras (em triplicata), tendo as dimensões de 1,43 m de profundidade, $80 \mathrm{~cm}$ de altura e $1 \mathrm{~m}$ de largura. No primeiro experimento, em cada composteira foram montadas as pilhas contendo três camadas intercaladas de $14 \mathrm{~kg}$ de carcaça triturada, $20 \mathrm{~kg}$ de maravalha e 6,6 L de água livre de cloro. Juntamente com a água foram adicionadas suspensões bacterianas de $S$. Senftenberg de forma a conter uma concentração final de $10^{8} \mathrm{UFC} \mathrm{mL}^{-1}$. Foi utilizado este sorovar por apresentar maior resistência térmica dentro do gênero (Ros-Chumillas et al., 2017). Destaca-se que as carcaças após trituradas foram homogeneizadas com maravalha para facilitar a ação dos microorganismos decompositores no interior da massa. Um segundo experimento foi conduzido, também em triplicata, utilizando carcaça de suínos em pedaços (picadas). Cada composteira foi composta por três camadas intercaladas contendo em média 15 $\mathrm{kg}$ de carcaça, $20 \mathrm{~kg}$ de maravalha, e 6,6 L de água livre de cloro. Juntamente com a água foram adicionadas suspensões bacterianas de $S$. Senftenberg de forma a conter uma concentração final de $10^{8} \mathrm{UFC} \mathrm{mL}^{-1}$. O experimento foi idealizado de acordo com estudos já publicados (Wilkinson, 2007).

\subsection{Monitoramento do comportamento térmico}

Entre as camadas de compostagem foram instalados termômetros em diferentes pontos para acompanhamento do comportamento térmico dos processos.

\subsection{Monitoramento da contagem de bactérias}

Para acompanhamento da mortalidade dos micro-organismos modelo, amostras compostas foram formadas a partir da 
coleta de um pool de 4 diferentes locais dentro de cada composteira. Após, $25 \mathrm{~g}$ desse pool foram submetidos a diluição seriada em solução salina $(0,9 \%)$ e posterior quantificação bacteriana. Para a quantificação de $E$. coli, as amostras foram submetidas à diluição seriada na base 10 em solução salina, e então semeadas por profundidade em ágar chromocult ${ }^{\circ}$ $\left(\right.$ Merck $\left.^{\circledR}\right)$, com incubação a $37^{\circ} \mathrm{C}$ por $24 \mathrm{~h}$ onde, posteriormente foram realizadas as contagens de colônias típicas conforme orientação do fabricante. Os resultados foram expressos em UFC. Para a quantificação de $S$. Senftenberg as amostras foram submetidas a diluição seriada na base $10 \mathrm{em}$ solução salina e então semeadas em Ágar XLD, incubadas a $37^{\circ} \mathrm{C}$ por $24 \mathrm{~h}$ e posteriormente quantificadas. Os resultados foram expressos em UFC. A metodologia de contagem bacteriana seguiu as recomendações APHA (2012).

\section{Resultados e Discussão}

\subsection{Compostagem em escala laboratorial}

A Figura 1 apresenta o acompanhamento da temperatura durante a compostagem em escala laboratorial de carcaças trituradas de suínos ao longo do tempo.

Figura 1. Temperatura observada durante a decomposição de carcaças de suínos triturados e compostado.

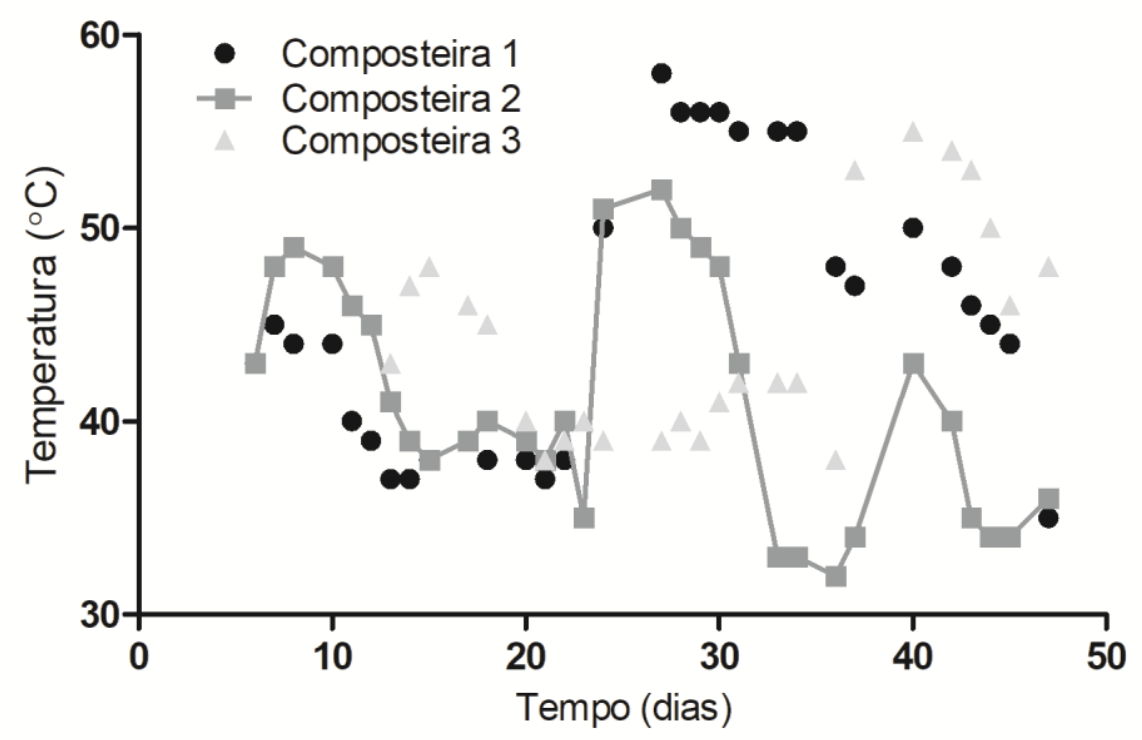

Fonte: Autores.

A temperatura apresentou um aumento nos primeiros 7 dias do processo, seguido de um decréscimo até os 18 dias. Após 24 dias do início do processo, o material foi revolvido, o que promoveu a oxigenação do sistema e consequentemente a reativação do processo de decomposição, comprovado pela elevação da temperatura acima de $50{ }^{\circ} \mathrm{C}$ (Figura 1). O processo de revolvimento é recomendado em outros estudos (Schloss et al., 2000; Guidoni et al., 2021) e frequentemente um processo adotado por produtores rurais em granjas avícolas sendo este manejo útil para situações similares. Um perfil de variação da temperatura semelhante foi observado por Lashermes et al. (2012), e justifica-se por conta das dimensões da composteira, onde experimentos em escala laboratorial podem perder calor para o ambiente com mais facilidade (Lashermes et al. 2012).

Durante o processo de compostagem foi acompanhada a sobrevivência de bactérias modelo. O comportamento microbiano durante a compostagem de carcaça de suínos trituradas estão apresentadas na Figura 2. É possível observar que foram necessários 35 dias para inativação da $S$. Senftenberg (Figura 2a) e E. coli (Figura 2b). Esse período foi necessário 
devido a oscilação da temperatura no início do processo.

Figura 2. Concentração de bactérias ao longo do experimento de compostagem de carcaças de suínos trituradas, sendo a) Salmonella Senftenberg e b) Escherichia coli.

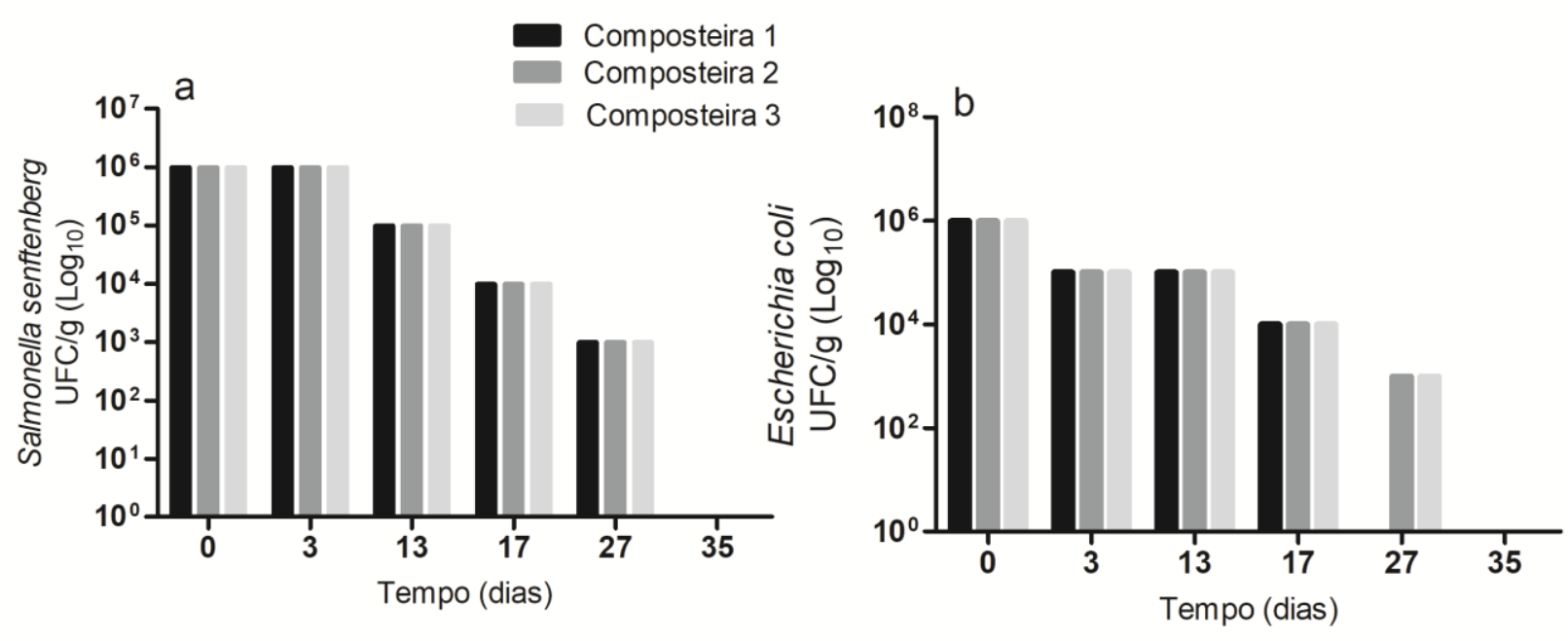

Fonte: Autores.

\subsection{Compostagem em escala piloto}

Durante o período experimental o $\mathrm{pH}$ ficou em torno de 8,4 $\pm 0,2$ e a umidade total com média de $70 \%$, o que corrobora ao reportado na literatura como condição ideal para o processo eficiente de compostagem de resíduos (Liang et al., 2003; Miguel et al., 2021). Desta forma, as bactérias envolvidas no processo de compostagem estiveram em condições adequadas para realizar uma eficiente degradação, o que pode ser observado também pela temperatura das composteiras (Figura 3), tanto para carcaças trituradas como para as em pedaços. Observa-se que nos primeiros 15 dias a temperatura ficou em torno de $60^{\circ} \mathrm{C}$. Como consequência, os micro-organismos patogênicos modelo utilizados foram totalmente inativados nos primeiros 5 dias. 
Figura 3. Acompanhamento da temperatura (média das 3 composteiras) nas composteiras em escola piloto contendo a) carcaças de suínos trituradas e b) carcaças de suínos em pedaços.
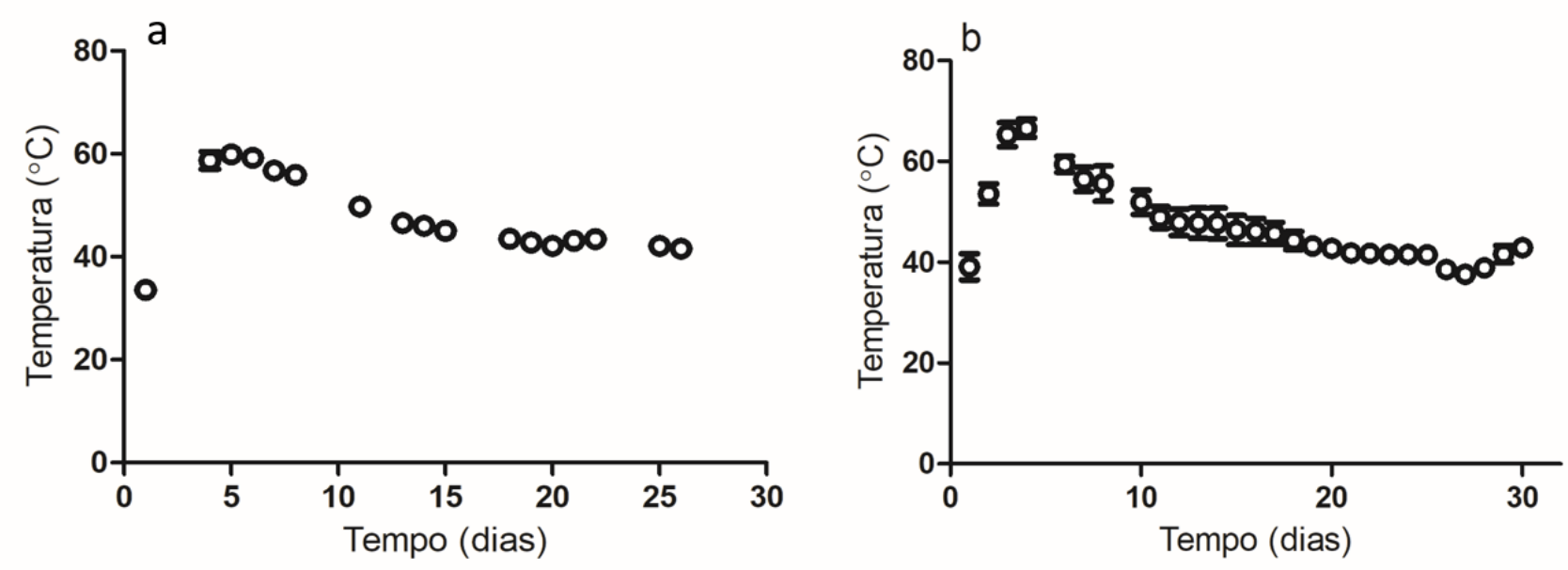

Fonte: Autores.

De acordo com a literatura, patógenos como a Salmonella spp. precisam de pelo menos $60^{\circ} \mathrm{C}$ de temperatura e permanecer nesta por pelo menos 5 a 7 dias para serem inativados (Singh et al., 2012). Na compostagem em escala laboratorial a temperatura ficou entre $50^{\circ} \mathrm{C}$ e $60^{\circ} \mathrm{C}$, o que estendeu o tempo de inativação total de bactérias para 9 dias (a contar do dia do revolvimento até a eliminação total). Já no experimento em escala piloto, a temperatura de $60^{\circ} \mathrm{C}$ foi atingida logo nos primeiros dias e como consequência, os micro-organismos patogênicos modelo foram eliminados a partir do $5^{\circ}$ dia de experimento. O mesmo comportamento foi observado por Pepin et al. (2020). Observa-se que o tempo de compostagem foi menor que os 120 dias geralmente observados a campo (Saviozzi et al., 2004). Isso deve-se ao fato de as carcaças estarem trituradas, e ou em pedaços, o que aumenta a superfície de contato entre o material a ser decomposto e os micro-organismos decompositores.

\section{Conclusão}

Os resultados do presente estudo indicam a aplicabilidade do método de compostagem para inativação de patógenos, desde que haja interação suficiente entre os parâmetros base, para que os micro-organismos decompositores produzam calor suficiente para que a temperatura fique acima de $60^{\circ} \mathrm{C}$.

Essa alternativa para destinação de carcaças de suínos é usualmente empregada e continua sendo útil, uma vez que as composteiras podem ser construídas na propriedade rural com baixo custo e manejo relativamente fácil, tornando-se uma fonte de material fertilizante, além de evitar o transporte de animais mortos por longas distâncias.

\section{Agradecimentos}

In memorian: Os autores agradecem e homenageiam o colega Valter Felício, que efetuou com dedicação, grande parte das coletas analisadas neste trabalho. Manifestamos nossa gratidão e carinho.

\section{Referências}

ABPA - Associação Brasileira de Proteína Animal - Relatório anual (2020). http://abpa-br.com.br/storage/files/relatorio-anual-2020.pdf. 
APHA. Standard Methods For The Examination Of Water And Wastewater. American Public Health Association, American Water Works Association, Water Environment Federation. (22a ed.), 2012.

Ajmal, M., Aiping, S., Awais, M., Ullah, M. S., Saeed, R., Uddin, S., \& Zihao, X. (2020). Optimization of pilot-scale in-vessel composting process for various agricultural wastes on elevated temperature by using Taguchi technique and compost quality assessment. Process Safety and Environmental Protection, 140, $34-45$.

Bhatia, A., Madan, S., Sahoo, J., Ali, M., Pathania, R., \& Kazmi, A. A. (2013). Diversity of bacterial isolates during full scale rotary drum composting. Waste management, 33(7), 1595-1601.

Biswas, S., Nazmi, A., Pitesky, M., Gallardo, R., \& Pandey, P. (2019). Thermal inactivation of Escherichia coli and Salmonella Typhimurium in poultry carcass and litter at thermophilic temperatures. Journal of Applied Poultry Research, 28(2), 307-317.

Chang, H. Q., Zhu, X. H., Jie, W. U., Guo, D. Y., Zhang, L. H., \& Yao, F. E. N. G. (2021). Dynamics of microbial diversity during the composting of agricultural straw. Journal of Integrative Agriculture, 20(5), 1121-1136.

Cooperband, L. (2002). The art and science of composting. Center for Integrated agricultural systems. https://static1.squarespace.com/static/55848984e4b0caf8e32b24b7/t/55a9ba2de4b048cfac18595d/1437186605227/ArtScienceofComposting.pdf

Costa, T., \& Akdeniz, N. (2019). A review of the animal disease outbreaks and biosecure animal mortality composting systems. Waste Management, 90, 121131.

de Mendonça Costa, L. A., de Mendonça Costa, M. S. S., Damaceno, F. M., Chiarelotto, M., Bofinger, J., \& Gazzola, W. (2021). Bioaugmentation as a strategy to improve the compost quality in the composting process of agro-industrial wastes. Environmental Technology \& Innovation, 22, 101478

Gamroth, M. J. (2012). Composting: An Alternative for livestock manure management and disposal of dead animals.

Lashermes, G., Barriuso, E., Le Villio-Poitrenaud, M., \& Houot, S. (2012). Composting in small laboratory pilots: Performance and reproducibility. Waste Management, 32(2), 271-277.

Guidoni, L. L., Martins, G. A., Guevara, M. F., Brandalise, J. N., Lucia, T., Gerber, M. D., \& Corrêa, É. K. (2021). Full-Scale Composting of Different Mixtures with Meal from Dead Pigs: Process Monitoring, Compost Quality and Toxicity. Waste and biomass valorization, 1-13.

Gwyther, C. L., Williams, A. P., Golyshin, P. N., Edwards-Jones, G., \& Jones, D. L. (2011). The environmental and biosecurity characteristics of livestock carcass disposal methods: A review. Waste Management, 31(4), 767-778.

Lepesteur, M. (2020). Human and livestock pathogens and their control during composting. Critical Reviews in Environmental Science and Technology, 1-46.

Liang, C., Das, K. C., \& McClendon, R. W. (2003). The influence of temperature and moisture contents regimes on the aerobic microbial activity of a biosolids composting blend. Bioresource technology, 86(2), 131-137.

Masin, C. E., Fernandez, M. E., Lescano, M. R., \& Zalazar, C. S. (2020). Bioconversion of agro-industrial wastes: Combined compost and vermicompost processes using Eisenia fetida for stabilization of poultry litter. International journal of recycling organic waste in agriculture, 9(2), 107-118.

Miguel, M. A., Kim, S. H., Lee, S. S., \& Cho, Y. I. (2021). Impact of Soil Microbes and Oxygen Availability on Bacterial Community Structure of Decomposing Poultry Carcasses. Animals, 11(10), 2937.

Monteiro, N. F., Lima, H. M. R., da Silva, F. L., Sousa, F. D. C. A., da Silva, W. C., de Macedo Reis, L. C., \& Monteiro, A. L. (2021). Atividade do óleo essencial de Eucalyptus Globulus no controle de bactérias da cavidade oral. Research, Society and Development, 10(14), e60101420387-e60101420387.

Nakasaki, K., Hirai, H., Mimoto, H., Quyen, T. N. M., Koyama, M., \& Takeda, K. (2019). Succession of microbial community during vigorous organic matter degradation in the primary fermentation stage of food waste composting. Science of the Total Environment, 671, 1237-1244.

Palaniveloo, K., Amran, M. A., Norhashim, N. A., Mohamad-Fauzi, N., Peng-Hui, F., Hui-Wen, L., \& Razak, S. A. (2020). Food waste composting and microbial community structure profiling. Processes, 8(6), 723.

Partanen, P., Hultman, J., Paulin, L., Auvinen, P., \& Romantschuk, M. (2010). Bacterial diversity at different stages of the composting process. BMC microbiology, 10(1), 1-11.

Pepin, B., Williams, T., Polson, D., Gauger, P., \& Dee, S. (2020). Survival of swine pathogens in compost formed from preprocessed carcasses. Transboundary and Emerging Diseases. 68, 2239-2249.

Ros-Chumillas, M., Garre, A., Maté, J., Palop, A., \& Periago, P. M. (2017). Nanoemulsified D-limonene reduces the heat resistance of Salmonella Senftenberg over 50 times. Nanomaterials, 7(3), 65.

Wang, Y., Tang, Y., Li, M., \& Yuan, Z. (2021). Aeration rate improves the compost quality of food waste and promotes the decomposition of toxic materials in leachate by changing the bacterial community. Bioresource Technology, 340, 125716.

Wilkinson, K. G. (2007). The biosecurity of on-farm mortality composting. Journal of Applied Microbiology, 102(3), 609-618. 